\title{
The effect of selective serotonin re-uptake inhibitors on cytochrome P4502D6 (CYP2D6) activity in human liver microsomes
}

\author{
H. K. CREWE ${ }^{1}$, M. S. LENNARD ${ }^{1}$, G. T. TUCKER ${ }^{1}$, F. R. WOODS ${ }^{2}$ \& R. E. HADDOCK \\ ${ }^{1}$ University Department of Medicine and Pharmacology, Section of Pharmacology and Therapeutics, Royal Hallamshire \\ Hospital, Sheffield S10 2JF, and ${ }^{2}$ Department of Drug Metabolism and Pharmacokinetics, SmithKline Beecham \\ Pharmaceuticals, The Frythe, Welwyn AL6 9AR
}

Inhibition of human cytochrome P4502D6 (CYP2D6)-catalysed metabolism can lead to clinically significant alterations in pharmacokinetics. Since there is evidence that the selective serotonin reuptake inhibitor (SSRI) class of antidepressant drugs might inhibit CYP2D6, the effects of five SSRIs on human liver microsomal CYP2D6 activity were compared with each other and with three tricyclic antidepressant drugs. On a molar basis, paroxetine was the most potent of the SSRIs at inhibiting the CYP2D6-catalysed oxidation of sparteine $\left(K_{\mathrm{i}}=0.15 \mu \mathrm{M}\right)$, although fluoxetine $(0.60 \mu \mathrm{M})$ and sertraline $(0.70$ $\mu \mathrm{M})$ had $K_{\mathrm{i}}$ values in the same range. Fluvoxamine $(8.2 \mu \mathrm{M})$ and citalopram $(5.1 \mu \mathrm{M})$ also inhibited CYP2D6 activity. The major circulating metabolites of paroxetine in man produced negligible inhibition. In contrast, norfluoxetine the active metabolite of fluoxetine, was a potent CYP2D6 inhibitor $(0.43 \mu \mathrm{M})$. CYP2D6 activity was also diminished by the tricyclic antidepressant drugs clomipramine $(2.2 \mu \mathrm{M})$, desipramine $(2.3 \mu \mathrm{M})$ and amitriptyline $(4.0 \mu \mathrm{M})$. These findings suggest that compounds with SSRI activity are likely to interact with human CYP2D6 in vivo with the potential of causing drug interactions.

Keywords cytochrome P4502D6 paroxetine fluoxetine sertaline citalopram
fluvoxamine

\section{Introduction}

The hepatic enzyme cytochrome P4502D6 (CYP2D6) (Nebert et al., 1991) plays an important role in the metabolism of several classes of clinically important drugs including neuroleptic, antiarrhythmic, tricyclic antidepressant and $\beta$-adrenoceptor blocking agents (Lennard, 1990). In vitro (Bloomer et al., 1992) and in vivo (Sindrup et al., 1991) studies have demonstrated that the selective serotonin reuptake inhibitor (SSRI) paroxetine is also a substrate for CYP2D6. Recent reports suggest that paroxetine and other members of this class of antidepressant drugs may also inhibit CYP2D6 (Brøsen \& Skjelbo, 1991; Brøsen et al., 1991; Sindrup et al., 1992; Westermeyer, 1991). Inhibition of CYP2D6-catalysed metabolism can lead to alterations in pharmacokinetics which, for those CYP2D6 substrates with a narrow therapeutic range, could have clinical significance. To determine whether the ability to interact with CYP2D6 is a common feature of SSRIs, the inhibitory effect of paroxetine on liver microsomal CYP2D6 activity was compared with that

of fluoxetine, sertraline, citalopram and fluvoxamine and the tricyclic antidepressant drugs clomipramine, desipramine and amitriptyline. The major metabolites of paroxetine (Dechant \& Clissold, 1991; Haddock et $a l ., 1989)$ and fluoxetine (Benfield et al., 1986) were also studied.

This work was presented in abstract form at the British Pharmacological Society Meeting, University of Glasgow, July 1991 (Crewe et al., 1991).

\section{Methods}

Paroxetine hydrochloride (S,R-enantiomer), its metabolites (sodium salts of M-I glucuronide and M-I sulphate, hydrochloride salts of M-I and M-II, and MIII free base) (Haddock et al., 1989) and norfluoxetine hydrochloride (racemate) were synthesised in the laboratories of SmithKline Beecham (Welwyn, U.K.). 
Sparteine sulphate, quinidine sulphate, amitriptyline hydrochloride, clomipramine hydrochloride, lignocaine base, metoprolol tartrate, desipramine hydrochloride, thioridazine hydrochloride and antipyrine were purchased from Sigma Chemical Co. (Poole, U.K.). Fluoxetine hydrochloride (racemate) was obtained from Eli Lilly and Co. Ltd (Basingstoke, U.K.), fluvoxamine maleate from Duphar Laboratories Ltd (Southampton, U.K.), sertraline hydrochloride (S,Senantiomer) from Pfizer Central Research (Sandwich, U.K.), citalopram hydrobromide (assumed to be the racemate) from Lundbeck Ltd (Luton, U.K.) and mexiletine from Boehringer (Bracknell, U.K.). Samples of a human liver (coded HL4), which had been genotyped as homozygous wild-type CYP2D6 (C. R. Wolf, personal communication), were used. The liver was obtained from a renal transplant donor with the approval of the Hospital Ethics Committee. Liver microsomes were prepared as described previously (Otton et al., 1988$)$. Microsomes ( $0.2 \mathrm{mg}$ protein) were incubated at $37^{\circ} \mathrm{C}$ for $40 \mathrm{~min}$ with sparteine (62.5 or 125 $\mu \mathrm{M})$ and an NADPH generating system in the presence or absence of the test compounds. The reaction was stopped by the addition of $6 \%(\mathrm{v} / \mathrm{v})$ perchloric acid. Mexiletine (12.5 ng) was then added as internal standard. A modification of the gas liquid chromatographic method of Otton et al. (1983) was used for the assay of 2-dehydrosparteine. Thus, the reaction was stopped with aqueous perchloric acid $(50 \mu \mathrm{l}, 6 \% \mathrm{v} / \mathrm{v})$ and methyl $t$-butyl ether was used instead of dichloromethane. Incubations were performed in duplicate and the mean rate of metabolite appearance was calculated. The rate of 2-dehydrosparteine formation was linear with respect to time and protein concentration. Inhibition constants were calculated from the intersection of plots of $1 /$ rate $v s$ inhibitor concentration using the method of Dixon (Cornish-Bowden, 1979). Lines were fitted by linear regression.

\section{Results and Discussion}

The rate of conversion of sparteine to dehydrosparteine was used as the index of CYP2D6 activity. Nineteen compounds were investigated as possible inhibitors of sparteine oxidase in human liver microsomes. Values of inhibition constants for these compounds obtained at two sparteine concentrations (approximately $K_{m}$ and $2 K_{m}$, Otton et al., 1983) are listed in Table 1 and a series of Dixon plots for the inhibition of sparteine oxidase are shown in Figure 1. Quinidine, thioridazine and metoprolol, are drugs known to be inhibitors of CYP2D6 (von Bahr et al., 1985) and were included as 'positive controls'. Lignocaine and antipyrine, which do not inhibit CYP2D6, were used as 'negative controls'.

On a molar basis, paroxetine was the most potent of

\section{References}

Benfield, P., Heel, R. C. \& Lewis, S. P. (1986). Fluoxetine: a review of its pharmacodynamic and pharmacokinetic properties and therapeutic efficacy in depressive illness.
Table 1 Inhibition constants $\left(K_{\mathrm{i}}\right)$ for the inhibition of 2-dehydrosparteine metabolism in human liver microsomes

\begin{tabular}{|c|c|}
\hline Compound & $\mathrm{K}_{i}(\mu M)$ \\
\hline Paroxetine & 0.15 \\
\hline M-I glucuronide* & $>200$ \\
\hline M-I sulphate* & 120 \\
\hline M-I & 16 \\
\hline M-II & 0.5 \\
\hline M-III & $>20$ \\
\hline Fluoxetine & 0.60 \\
\hline Norfluoxetine* & 0.43 \\
\hline Sertraline & 0.70 \\
\hline Citalopram & 5.1 \\
\hline Fluvoxamine & 8.2 \\
\hline Clomipramine & 2.2 \\
\hline Desipramine & 2.3 \\
\hline Amitriptyline & 4.0 \\
\hline Quinidine & 0.03 \\
\hline Thioridazine & 0.52 \\
\hline Metoprolol & 37 \\
\hline Lignocaine & 200 \\
\hline Antipyrine & $>3000$ \\
\hline
\end{tabular}

*Major metabolites.

the SSRIs at inhibiting the CYP2D6-catalysed oxidation of sparteine, although fluoxetine and sertraline had $K_{\mathrm{i}}$ values in the same range. Fluvoxamine and citalopram also inhibited CYP2D6 activity. M-I glucuronide and sulphate, the major circulating metabolites of paroxetine in man, produced negligible inhibition. In contrast norfluoxetine, the active metabolite of fluoxetine, was a potent CYP2D6 inhibitor. The three tricyclic antidepressant drugs tested also diminished CYP2D6 activity. The results from the positive and negative control compounds were as anticipated.

There is evidence that CYP2D6 is involved in the processing of dopamine in the brain (Niznik et al., 1990). However, the potency of inhibition of CYP2D6 by SSRIs does not appear to be related to their potency as inhibitors of the reuptake of 5-hydroxytryptamine into synaptosomes (Dechant \& Clissold, 1991; Haddock et al., 1989; Koe et al., 1983), suggesting that CYP2D6 is not involved in the transport of neuronal 5-hydroxytryptamine.

In summary, all of the SSRI drugs tested were potent inhibitors of liver microsomal CYP2D6. In clinical practice fluoxetine has been shown to increase blood concentrations of tricyclic antidepressant drugs to toxic levels in depressed patients (Westermeyer, 1991). Since paroxetine, sertraline, citalopram and fluvoxamine are prescribed at doses comparable with or greater than that of fluoxetine, our findings suggest that compounds with SSRI activity are likely to interact with human CYP2D6 in vivo and with the potential to cause predictable drug interactions.
Drugs, 41, 225-253.

Bloomer, J. C., Woods, F. R., Haddock, R. E., Lennard, M. S. \& Tucker, G. T. (1992). The role of cytochrome 

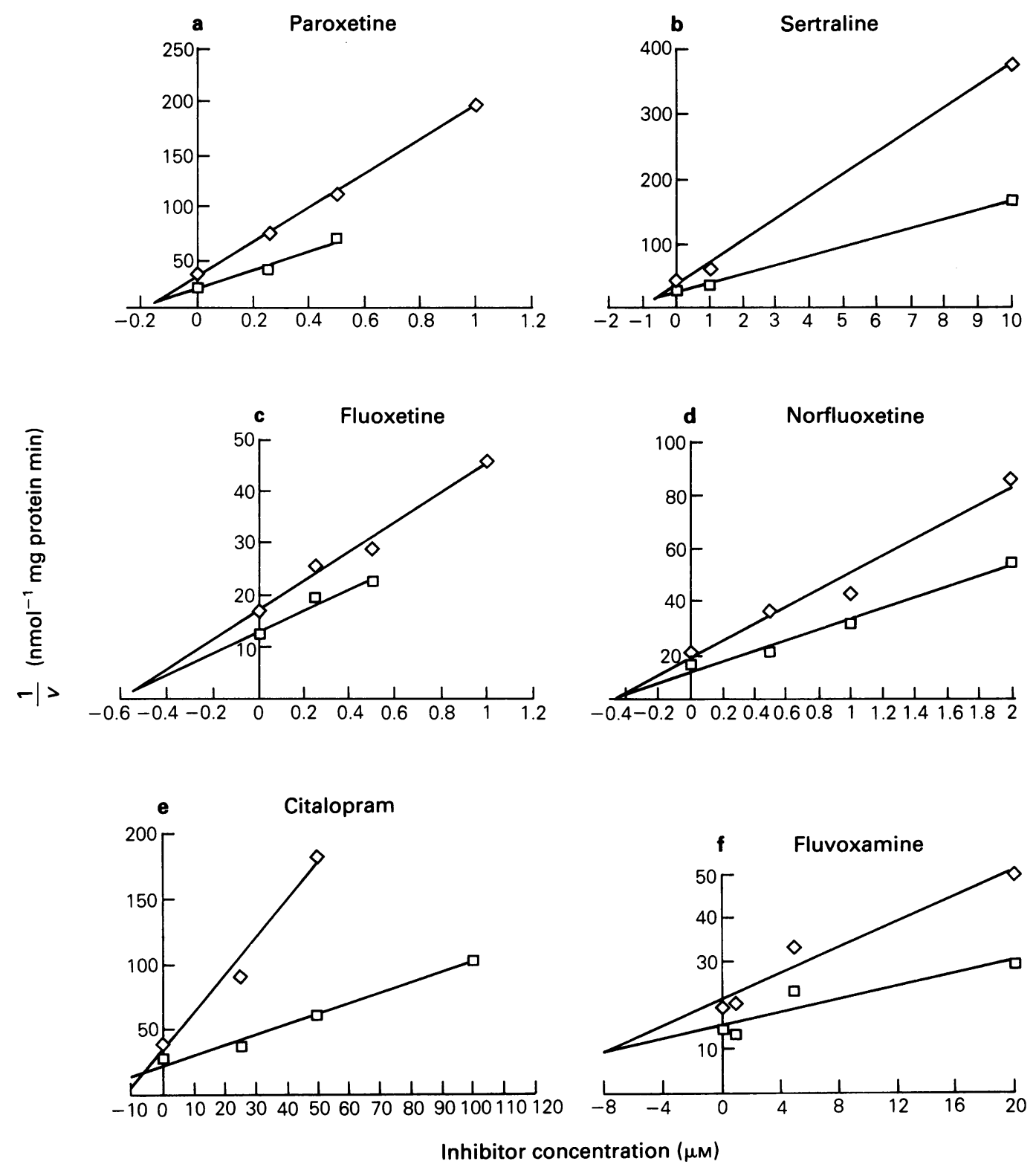

Figure 1 Dixon plots for the inhibition by a) paroxetine, b) sertraline, c) fluoxetine, d) norfluoxetine, e) citalopram and f) fluvoxamine of 2-dehydrosparteine appearance in human liver microsomes (diamonds $=6.25 \mu \mathrm{M}$ sparteine; squares $=125 \mu \mathrm{M}$ sparteine).

P4502D6 in the metabolism of paroxetine by human liver microsomes. Br. J. clin. Pharmac., 33, 521-523.

Brøsen, K. \& Skjelbo, E. (1991). Fluoxetine and norfluoxetine are potent inhibitors of P450IID6-the source of the sparteine/debrisoquine oxidation polymorphism. $\mathrm{Br}$. J. clin. Pharmac., 32, 136-137.

Brøsen, K., Gram, L. F. \& Kragh-Sorensen, P. (1991). Extremely slow metabolisers of amitriptyline but normal metabolisers of imipramine and desipramine in an extensive metaboliser of sparteine, debrisoquine and mephenytoin. Ther. Drug Monit., 13, 177-182.

Cornish-Bowden, A. (1979). Fundamentals of enzyme kinetics, p. 81. London: Butterworths.

Crewe, H. K., Lennard, M. S., Tucker, G. T., Woods, F. R. \& Haddock, R. E. (1991). The effect of paroxetine and other specific 5-HT re-uptake inhibitors on cytochrome P450IID6 activity in human liver microsomes. Br. J. clin. Pharmac., 32, 659P.

Dechant, K. L. \& Clissold, S. P. (1991). Paroxetine: a review of its pharmacodynamic and pharmacokinetic properties, and therapeutic potential in depressive illness. Drugs, $\mathbf{4 1}$, 225-253.
Haddock, R. E., Johnson, A. M., Langley, P. F., Nelson, D. R., Pope, J. A., Thomas, D. R. \& Woods, F. R. (1989) Metabolic pathways of paroxetine in animals and man and the comparative pharmacological properties of its metabolites. Acta psychiat. Scand., 80 (suppl. 350), 24-26.

Koe, B. K., Weissman, A., Willard, M. \& Browne, R. G. (1983). Sertraline, 1S,4S-N-methyl-4-(3,4-dichlorophenyl)1,2,3,4-tetrahydro-1-naphthylamine, a new uptake inhibitor with selectivity for serotonin. J. Pharmac. exp. Ther., 226, 686-700.

Lennard, M. S. (1990). Genetic polymorphism of sparteine/ debrisoquine oxidation: a reappraisal. Pharmac. Toxicol., 67, 273-283.

Nebert, D. W., Nelson, D. R., Coon, M. J., Estabrook, R. W., Feyereisen, R., Fujii-Kuriyama, Y., Gonzalez, F. J., Guengerich, F. P., Gunsalus, I. C., Johnson, E. F., Loper, J. C., Sato, R., Waterman, M. R. \& Waxman, D. J. (1991). The P450 superfamily: update on new sequences, gene mapping and recommended nomenclature. DNA Cell Biol., 10, 1-14.

Niznik, H. B., Tyndale, R. F., Sallee, F. R., Gonzalez, F. J., Hardwick, J. P., Inaba, T. \& Kalow, W. (1990). The 
dopamine transporter and cytochrome P450IID1 (debrisoquine 4-hydroxylase) in brain: resolution and identification of two distinct $\left[{ }^{3} \mathrm{H}\right] \mathrm{GBR}-12935$ binding proteins. Arch. Biochem. Biophys., 276, 424-432.

Otton, S. V., Inaba, T. \& Kalow, W. (1983). Inhibition of sparteine oxidation in human liver by tricyclic antidepressants and other drugs. Life Sci., 32, 795-800.

Otton, S. V., Crewe, H. K., Lennard, M. S., Tucker, G. T. \& Woods, H. F. (1988). Use of quinidine inhibition to define the role of the sparteine/debrisoquine cytochrome P450 in metoprolol oxidation by human liver microsomes. J. Pharmac. exp. Ther., 247, 242-247.

Sindrup, S. H., Brøsen, K., Gram, L. F., Hallas, J., Skjelbo, E., Allen, A., Allen, G. D., Cooper, S. M., Mellows, G.,
Tasker, T. C. G. \& Zussman, B. D. (1992). The relationship between paroxetine and sparteine oxidation polymorphism. Clin. Pharmac. Ther., 51, 278-287.

von Bahr, C., Spina, E., Birgersson, C., Ericsson, O., Goransson, M., Henthorn, T. \& Sjoqvist, F. (1985). Inhibition of desmethylimipramine 2-hydroxylation by drugs in human liver microsomes. Biochem. Pharmac., 34, 2501-2505.

Westermeyer, J. (1991). Fluoxetine-induced tricyclic toxicity: extent and duration. J. clin. Pharmac., 31, 388-392.

(Received 23 December 1991, accepted 27 March 1992) 